\title{
A FORMAÇÃO CONTINUADA DAS DOCENTES DO CURSO NORMAL DO COLÉGIO NOSSA SENHORA DO PATROCÍNIO (PATROCÍNIO - MG, 1947-1971) E A EDUCAÇÃO ESCOLAR COMO ESTRATÉGIA DA "RESTAURAÇÃO CATÓLICA"
}

\author{
Geraldo Gonçalves de Lima \\ Instituto Federal de Educação, Ciência e Tecnologia do Triângulo Mineiro (IFTM) \\ Décio Gatti Júnior \\ Universidade Federal de Uberlândia (UFU)
}

\begin{abstract}
RESUMO
O trabalho docente era assumido pelas próprias religiosas da Congregação. O presente artigo tem por objetivos: compreender os valores católicos como base inspiradora; descrever os desafios do ensino e o trabalho das religiosas mestras; discutir as principais questões burocráticas inerentes às perspectivas da formação acadêmica e continuada. $\mathrm{O}$ período abrange o Decreto Estadual 2.400 (07/02/1947), quando há o mandato para o Ensino Normal de $2 .^{\circ}$ ciclo, do Colégio Normal Nossa Senhora do Patrocínio. Se encerra quando o Ensino Normal é extinto com a Lei 5.692/71. Os "Cursos de Férias" eram frequentados para garantir não só a atualização dos conhecimentos e práticas, mas também como atendimento às prerrogativas legais. Os procedimentos metodológicos foram a pesquisa bibliográfica de alguns autores como Azzi (1992), Manacorda (2004) e Segers et all (1995); no exame interpretativo de documentos da Igreja Católica, como a Encíclica papal "Divini Illius Magistri", Pio XI; na investigação da Lei Orgânica do Ensino Normal (1946); e, finalmente, no tratamento de fontes documentais presentes na secretaria do Colégio Normal Nossa Senhora do Patrocínio. A formação de normalistas do Colégio Normal Nossa Senhora do Patrocínio consistia em parte da estratégia católica de "restauração".
\end{abstract}

Palavras-chave: História das idéias pedagógicas católicas; ensino de História da Educação; formação docente continuada.

\section{THE CONTINUING TRAINING OF THE TEACHERS OF THE COURSE NORMAL OF COLÉGIO NOSSA SENHORA DO PATROCÍNIO (PATROCÍNIO - MG, 1947-1971) AND THE SCHOOL EDUCATION AS A STRATEGY OF "CATHOLIC RESTORATION".}

\begin{abstract}
The teaching was assumed by their own religious of the congregation. This article aims: to understande the basic catholics values as inspiring; to describe the challenges of teaching and the work of religious master; to discuss the key issues inherent in bureaucratic perspectives of academic and continuing. The period covers the Sate Decrre 2400 (07/02/1947), when the mandate for the Normal School, Second Cycle, Colégio Normal Nossa Senhora do Patrocínio. Ends when the Normal School is extinguesed with the Law 5.692/71. The "Holiday courses" were frequented not only to ensure the updating of knowledge and practices, but also as meeting the legal prerogatives. The methodological procedures were theliterature of some authors as Azzi (1992), Manacorda (2004) and Segers et al (1995), the interpretive examination of
\end{abstract}


documents of the Catholic Church, as the Papal Encyclical "Divini Illius", Pio XI; research in the Organic Law of Education Normal (1946), and finally, in the treatment of documentary sources present in the office of the Colégio Normal Nossa Senhora do Patrocínio. The course of normal consisted in part of the strategy "Catholic restoration."

Keywords: History of Catholic teaching ideas; teaching History of Education; continuing training of the teachers.

Com a expansão da rede escolar mantida pela Igreja Católica Apostólica Romana em fins do século XIX e primeira metade do século XX, como forma de divulgação dos ideais e dos valores dogmáticos frente aos desafios do mundo contemporâneo, o Vaticano empreendeu uma série de políticas de estímulo às congregações e ordens religiosas, tanto masculinas como femininas. Um dos maiores mecanismos de doutrinação católica foi a educação escolar, assumida pelos religiosos, principalmente em continentes como África, Ásia e América.

O presente trabalho tem por objetivos: compreender os valores religiosos católicos como base inspiradora para a atuação docente no Curso Normal de Patrocínio - Minas Gerais; descrever os desafios do ensino da disciplina História da Educação no Curso Normal e o trabalho das religiosas mestras no Colégio Normal Nossa Senhora do Patrocínio; discutir as principais questões burocráticas inerentes à atuação docente e as perspectivas da formação acadêmica e continuada das religiosas mestras.

O recorte temporal da presente investigação se justifica pelo contexto da publicação da Lei Orgânica do Ensino Normal (1946), assim como pela publicação do Decreto Estadual 2.400 (07/02/1947), de Minas Gerais, quando há o mandato para ministrar o Ensino Normal de 2. ${ }^{\circ}$ ciclo, sob responsabilidade do Colégio Normal Nossa Senhora do Patrocínio. Por isso, há o aparecimento da disciplina História da Educação no currículo do Curso Normal apenas a partir de 1947. E, por fim, o recorte temporal se encerra quando o Ensino Normal é extinto com a Lei de Reforma do $1 .^{\circ}$ e 2..$^{\circ}$ Graus (Lei 5.692/71), ocasião em que é transformado numa das habilitações específicas do ensino profissionalizante.

O trabalho docente do Colégio Normal Nossa Senhora do Patrocínio era assumido em grande parte pelas próprias religiosas, belgas e brasileiras, da Congregação das Irmãs do Sagrado Coração de Maria de Berlaar. A preocupação com a formação acadêmica e continuada das mestras religiosas se torna uma constante, no sentido de buscar o sentido da preparação técnica para o exercício das funções docentes no Curso Normal e a adequação às novas exigências legais para o funcionamento do Curso Normal.

A atuação das religiosas da Congregação das Irmãs do Sagrado Coração de Maria de Berlaar como professoras na formação de normalistas do Colégio Normal Nossa Senhora do Patrocínio tem seus fundamentos em valores religiosos católicos que remontam às origens das ordens religiosas ainda no período medieval, na Europa. Além dos beneditinos, outra ordem teve muita influência sobre a espiritualidade e o carisma da Congregação das Irmãs: os agostinianos. As ordens "mendicantes" mais influentes sobre a espiritualidade e o carisma da Congregação das Irmãs são os franciscanos e os dominicanos. Basicamente, a proposta de regra de vida de tais ordens se caracteriza pela vivência da oração penitente e da pobreza radical, assim como a prática da evangelização por meio da pregação e da caridade aos mais pobres, doentes e desvalidos socialmente.

Acrescente-se que, exatamente no início do século XIII, quando as universidades se consolidam e se difundem, surgem as novas ordens 
religiosas: os dominicanos, sobretudo, e os franciscanos. Ambos renovam escolas e estudos, e realizam ação missionária externa. Os dominicanos dedicam-se particularmente à teologia, criando centros de estudo em conflito com os públicos; e os franciscanos, embora a Regra de São Francisco prescrevesse que os frades que não soubessem ler e escrever não se preocupassem em aprendê-lo (non curent nescientes litteras discere), dedicaram-se particularmente às artes liberais: o autor de uma das mais difundidas gramáticas medievais, Alexandre de Villadei, era um franciscano. Quando a conteúdo, ouvintes e sedes, já estamos bem longe do tradicional ensino monástico. As novas ordens religiosas têm uma função decisiva na evolução da nova cultura urbana. (MANACORDA, 2004, p. $146-7$ )

Contudo, foi o século XIX que tornou-se marcante pela expansão dos Sistemas Nacionais de Ensino europeus e pelo esforço em empreender a universalização do ensino primário, preferencialmente mantido pelo Estado, e de caráter laico. Outro detalhe contextual deste momento também é a consolidação de algumas doutrinas consideradas distintas das concepções católicas e consideradas perniciosas para o progresso humano, do ponto de vista cristão católico: racionalismo, protestantismo, maçonaria, liberalismo, positivismo, socialismo, comunismo e anarquismo. Como reafirmação de seus valores básicos, a Igreja Católica publica alguns documentos voltados para a difusão dos pressupostos fundamentais, por exemplo, da sua doutrina social. Um caso típico e bastante conhecido é a publicação da Encíclica Rerum Novarum (1891), de Leão XIII, em que aprova boa parte das reivindicações dos direitos sociais dos movimentos operários, mas criticando as idéias socialistas, comunistas e anarquistas ao defender o direito à propriedade privada, dentre outros.

Nesse sentido, são muitas as ações da Igreja Católica no sentido de empreender estratégias para a retomada da hegemonia doutrinária diante dos desafios mundanos em fins do século XIX e início do século XX. Há, assim, o movimento ultramontano, surgido no início do século XIX na França, que prescreve a autoridade papal como referência em termos doutrinais, de política, de fé e de disciplina moral (Roma, sede da Igreja Católica, situada além dos Montes Alpes). No Brasil, o movimento reformista católico se inicia com as obras de D. Romualdo Antônio de Seixas (1787-1860), Arcebispo da Bahia, e D. Antônio Ferreira Viçoso (1787-1875), Arcebispo de Mariana, no embate contra o catolicismo de tradição lusitana e popular, buscando a afirmação da tradição e da vivência sacramental, sobretudo a Eucaristia, nos moldes tridentinos.

A implantação e consolidação do movimento se deve ao espírito empreendedor de um grupo de bispos que se dispuseram a transformar a fisionomia da Igreja do Brasil. Cabe a ele pois, com muita razão, a designação de bispos reformadores. O movimento é de cunho marcadamente hierárquico, pois são os prelados que programam a reforma e zelam por sua aplicação. Trata-se, pois, de reforma autoritária, imposta de cima para baixo, sem participação popular no projeto. Esses prelados têm freqüentemente diante dos olhos dois grandes nomes da era tridentina: São Carlos Borromeu, o grande reformador da diocese de Milão na Itália, e frei Bartolomeu dos Mártires, o reformador da diocese de Braga, em Portugal. (AZZI, 1992, p. 30 - 1) 
A partir dos fins do Império brasileiro (década de 1880), a Igreja Católica Apostólica Romana tem uma mudança crucial em sua atitude perante as questões doutrinárias, políticas e sociais. Parte da estratégia estava justamente no apoio por parte do bispado brasileiro na vinda e instalação de ordens e congregações religiosas européias, sejam masculinas ou femininas, como forma de consolidar as ações pastorais da Igreja Católica junto à sociedade brasileira, em todos os seus segmentos e classes.

A justificativa e a necessidade de implantação e apoio aos movimentos de Ação Católica no Brasil é reforçada pela publicação da Encíclica papal "Ubi Arcano Dei" (1922), de Pio XI. Basicamente, o teor de tal documento perpassa pelo estímulo aos fiéis leigos católicos, no sentido de organização e formação de entidades, legiões e grupos para ajudar a Igreja Católica no combate aos obstáculos da "cristianização" do mundo. Assim, o conjunto de tais ações leigas ficou conhecido como Ação Católica, sob inspiração do lema do pontificado de Pio XI: "restaurar todas as coisas em Cristo".

Como fundação específica desse período, surge a Ação Católica, considerada o braço direito da hierarquia eclesiástica. A Ação Católica procura inocular nos leigos cristãos um sentido de presença ativa na sociedade, dentro de um espírito de ordem e disciplina eclesiástica. A função dos militantes católicos é manter-se numa linha de fidelidade absoluta à Santa Sé, cuja vontade é expressa através do episcopado. Segundo a concepção da época, esses movimentos leigos não são feitos para a transformação social da sociedade, mas apenas para sua transformação espiritual. Em suma, o que se requeria de um leigo católico era que ele fosse capaz de proclamar sua fé sem respeito humano, permanecendo fiel às práticas religiosas. A sociedade seria transformada pela multiplicação dos católicos verdadeiramente cumpridores de suas obrigações morais. Ainda merecem destaque nesse período a fundação do Centro Dom Vital, destinado a reunir a intelectualidade católica na sua luta por maior influência da Igreja nas diretrizes políticas e sociais do país, visando sempre à salvaguarda dos interesses eclesiásticos. (AZZI, 1994, p. 28)

Por outro lado, especificamente referente ao tema da educação cristã da juventude, o Papa Pio XI também publica, em 1929, a Encíclica "Divini Illius Magistri”, em que exorta os católicos à reflexão sobre as condições, a prioridade e os efeitos da doutrinação católica sobre a juventude, especialmente.

Pio XI demonstra sua preocupação enquanto pastor e chefe da Igreja Católica perante os jovens, educadores, pais e mães e aponta a escassez de princípios claros e determinantes para a hegemonia doutrinária católica.

Aponta também a necessidade de um posicionamento efetivo da Igreja em relação às discussões e reformas ocorridas em torno do sistema de ensino em diversos países do mundo.

Defende que nunca houve até os fins da década de 1920 tantas especulações em torno de novas teorias acerca das concepções educacionais, métodos de ensino e finalidades educacionais, com o intuito de promoção da felicidade terrena.

Segundo tais princípios difundidos pelo racionalismo e doutrinas voltadas para o desenvolvimento meramente material, o progresso humano se identifica com a felicidade conquistada com o acúmulo de bens materiais, equivocadamente. Assim, 
É portanto da máxima importância não errar na educação, como não errar na direção para o fim último com o qual está conexa íntima e necessariamente toda a obra da educação. $\mathrm{Na}$ verdade, consistindo a educação essencialmente na formação do homem como ele deve ser e portar-se, nesta vida terrena, em ordem a alcançar o fim sublime para que foi criado, é claro que, assim como não se pode dar verdadeira educação sem que esta seja ordenada para o fim último, assim na ordem atual da Providência, isto é, depois que Deus se nos revelou no Seu Filho Unigênito que é o único "caminho, verdade e vida", não pode dar-se educação adequada e perfeita senão a cristã. Daqui ressalta, com evidência, a importância suprema da educação cristã, não só para cada um dos indivíduos, mas também para as famílias e para toda a sociedade humana, visto que a perfeição desta, resulta necessariamente da perfeição dos elementos que a compõem. Dos princípios indicados aparece, de modo semelhante, clara e manifesta, a excelência (que bem pode dizer-se insuperável) da obra da educação cristã, como aquela que tem em vista, em última análise, assegurar o Sumo Bem, Deus, às almas dos educandos, e a máxima felicidade possível, neste mundo, à sociedade humana. (PIO XI, 1929)

$\mathrm{Na}$ década de 1940, a promoção dos congressos sob responsabilidade da Confederação Interamericana de Educação Católica demonstra a tentativa de conduzir as atividades de ensino das instituições de ensino americanas em consonância com os pontos básicos definidos pela Santa Sé. A instalação do Colégio Normal Nossa Senhora do Patrocínio em 1928 é resultado da aliança entre o Estado (responsável pela educação pública), a oligarquia rural (desejosa de garantir uma instituição de ensino para a educação conservadora de suas filhas) e a Igreja Católica (interessada em oferecer a educação escolarizada como estratégia para a "recristianização" da sociedade).

As missões assumidas pela Congregação das Irmãs do Sagrado Coração de Maria de Berlaar no Brasil, durante o século XX, sobretudo em termos de escolas, hospitais, asilos e orfanatos, condizem com a proclamação de Pio XI para a formação educacional da juventude cristã católica. A Congregação das Irmãs de Berlaar - Bélgica consegue, nesse intuito, ampliar seus horizontes missionários e apostólicos, assim como colaborar para a consecução dos preceitos divulgados por Sua Santidade junto à reafirmação dos principais valores católicos.

O corpo docente das escolas mantidas e dirigidas pela congregação era basicamente composto por religiosas, em harmonia com as estratégias amplamente difundidas pelo clero católico. A formação religiosa de tais mestras acontecia como na maioria das ordens e congregações católicas. De forma geral, a candidata à vida religiosa se dedicava as práticas formativas em três fases: o Postulantado, o Noviciado e o Juniorato.

Moças que se sentiam atraídas pela vida religiosa [...] não se tornavam, de um dia para outro, Irmãs do Sagrado Coração de Maria. A vocação devia primeira ser testada quanto à firmeza e sua autenticidade durante um período de experiência e de formação. A candidata devia familiarizarse com a especificidade, sobretudo a espiritualidade, a Regra de Vida e os Estatutos da Congregação. Devia também ser bem preparada ao modode-viver no convento, à mentalidade e atitude certa de Irmã. Por isso, os votos perpétuos eram precedidos por um amplo e bem dividido período de introdução. Os Estatutos de 1928, repetiam mais de uma vez, de maneira pormenorizada e numa versão ligeiramente modificada, os ritos e 
as condições desta fase inicial de iniciação. [...] a superiora informava-se primeiro sobre o passado, a saúde e as "credenciais dela. Fazia-se um acordo com os pais, quanto ao dote. Após a aceitação, a jovem ficava como postulante, no mínimo por seis meses, um período de experiência, no qual ela, separada das Irmãs professas, podia continua eventualmente, os estudos. No caso de dúvida sobre a autenticidade da vocação este período podia ser prolongado por mais um semestre. Depois vinha a vestição do hábito ou $\mathrm{o}$ afastamento. Antes de vestir o hábito, a postulante passava ainda por uma investigação (para saber se ela agia "em plena consciência e total liberdade") por um padre delegado da diocese, tinha que fazer um retiro de oito dias e confessar-se de maneira profunda. Após o Postulantado vinha, geralmente num dia de festa Marial, a celebração da vestição do hábito, um momento memorável não somente para a pessoa em questão que se livrava literalmente e simbolicamente da roupa secular, mas também para toda a comunidade. [...] após vestir o hábito, a noviça ficava durante um ano sob a orientação de uma Mestra de noviças e da assistente dela e começava, estritamente separada das professas, a própria preparação à vida religiosa. [...] durante o noviciado, faziam-se o estudo e a aplicação prática da Regra de Vida de Agostinho e dos Estatutos da Congregação. Os estudo normais eram interrompidos. Toda a formação era em função do conhecimento e da prática da atitude religiosa e das virtudes como pobreza, castidade, silêncio, humildade, obediência etc. A maior parte do tempo ia para trabalho doméstico. As noviças eram de fato mobilizadas no trabalho de cozinha, na manutenção do convento e do jardim, no acompanhamento das alunas do pensionato. Quase não havia tempo previsto para leitura de formação geral ou religiosa. Deste modo, a noviça já tinha uma experiência da vida que lhe esperava na Congregação, onde faltava sempre gente para muito trabalho. Se uma noviça não desse satisfação por uma ou outra razão, ela podia ainda sempre ser afastada. [...] Como preparação aos votos temporários, a noviça era interrogada por um padre e fazia um retiro de oito dias. Os votos temporários de pobreza, castidade e obediência podiam ser renovados de ano em ano (a partir de 1940 a cada três anos) durante três anos ou até a Irmã chegar aos 21 anos de idade, exigidos para os votos perpétuos. Enquanto isso, a Irmã já era totalmente integrada ao trabalho apostólico da Congregação. [...] As Irmãs com votos perpétuos eram incentivadas para renovar individual e regularmente os seus votos, diariamente, na hora de dormir. Isso acontecia coletivamente e de maneira solene na festa de Nossa Senhora da Apresentação ou no fim do retiro anual. (SEGERS et al, 1995, p. 206 10)

Além da formação especificamente religiosa, as Irmãs da Congregação do Sagrado Coração de Maria de Berlaar também buscavam desenvolver a formação acadêmica de seus membros em seus próprios educandários, freqüentando especialmente o Curso Normal, para aquelas que se dedicaram às atividades de ensino. Complementando a formação acadêmica inicial, há também a preocupação em buscar condições para a formação continuada de suas educadoras religiosas, seja no âmbito do ensino ou da saúde.

A execução do ensino propriamente dito, na maior parte dos casos, estava a cargo das religiosas que, na verdade, acumulavam inúmeras funções, tanto na escola, nas atividades de apostolado, como na ala conventual. O trabalho de uma religiosa da Congregação das Irmãs do Sagrado Coração de Maria de Berlaar era bastante árduo e rigidamente executado, conforme horários bem estabelecidos para a oração, repouso, 
atividades administrativas e docentes na escola, outras atividades voltadas para o apostolado, trabalhos manuais etc. A disciplina e a severidade nos comportamentos sempre foram valorizados nas Ordens e Congregações religiosas como forma de manter a ordem e o respeito às regras de convivência em comunidade.

Especificamente na Escola Normal Nossa Senhora do Patrocínio, as mestras religiosas da Congregação ofereciam os seguintes cursos: Jardim; Primário; Admissão; Ginasial; Normal de $1 .^{\circ}$ grau.

Após a publicação da Lei Orgânica do Ensino Normal (1946), com a publicação do Decreto Estadual 2.400 (07/02/1947), há o mandato para ministrar o Ensino Normal de 2. ${ }^{\circ}$ ciclo, passando o educandário a se denominar Colégio Normal Nossa Senhora do Patrocínio. Nesse sentido, há o aparecimento da disciplina História da Educação no currículo do Curso Normal apenas a partir de 1947.

Assim, no Curso Normal do Colégio Normal Nossa Senhora do Patrocínio, a primeira professora a assumir o ensino da disciplina de História da Educação é a Irmã Maria Jesuína Diniz (Rosalina Diniz), nascida em Betim - Minas Gerais, no dia 14 de janeiro de 1912, filha de Jesuíno da Silva Diniz e Rita Cândida de Jesus.

Faleceu em Patrocínio - Minas Gerais, no dia 08/06/1990, onde ainda atuava como religiosa e atualmente sepultada. Seu registro de professora, junto à Diretoria do Ensino Secundário do Ministério da Educação e Saúde é o n. ${ }^{\circ}$ 11.157, conforme o Decreto-Lei n. ${ }^{\circ}$ 8.777 de 22/01/1946. Em relação à História da Educação, atuou como professora entre os anos 1949 e 1953. Também atuou como Secretária no período de 1940 a 1953.

Figura 1 - Turma $4 .{ }^{a}$ Série Ginasial - 1950

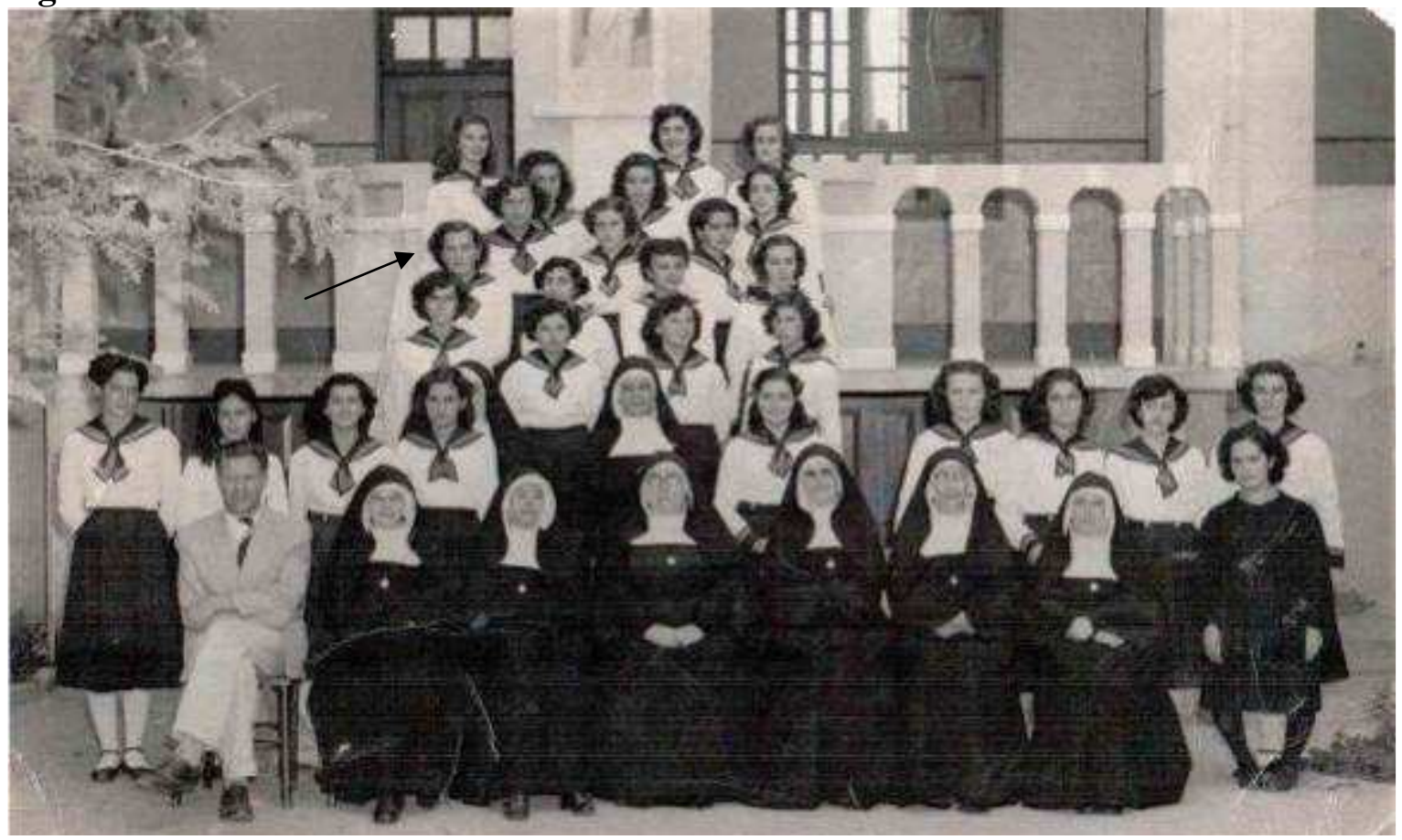

De pé: Ir. Maria Jesuína. Sentados - da esquerda para a direita: Leonardo Smeele, Ir. Gislene, Ir. Joselita, Ir. Gilberta, Ir. Solange, Ir. Evangelina; Ir. Osmunda). Acervo particular: Zulma Laura de Oliveira (indicada na foto pela seta).

Por sua vez, a segunda professora da disciplina História da Educação é Maria do Rosário Lemos Borges, nascida a 3 de outubro de 1922, em Serra do Salitre, na época pertencente ao município de Patrocínio - Minas Gerais. Oriunda de uma família de 
agricultores, com onze filhos, dos quais todas as seis filhas freqüentaram como internas o Colégio Normal Nossa Senhora do Patrocínio.

Maria do Rosário Lemos Borges freqüentou o Colégio entre 1935, quando passou a cursas o $3 .^{\circ}$ ano primário, até sua formatura como normalista, cuja cerimônia solene ocorreu no dia 04 de dezembro de 1941. Formada no Curso Normal, atuou ainda leiga como professora, no período de 1944 a 1951.

Ingressou como Postulante na Congregação das Irmãs do Sagrado Coração de Maria de Berlaar em 02 de julho de 1952. Posteriormente, se torna também, Secretária, no período de 1954 a 1957 do referido educandário. A Irmã Maria do Rosário Lemos Borges atuou como professora nas seguintes disciplinas: História e Filosofia da Educação, Sociologia Educacional, Geografia e História do Brasil, sob o Certificado n. ${ }^{\circ} 39$, do Departamento do Ensino Secundário e Superior, subordinado à Secretaria da Educação de Minas Gerais.

\section{Figura 2 - Professora Maria do Rosário Lemos Borges - Paraninfa da Turma de Normalistas de 1949 (Acervo particular: Maria Fidalma do Nascimento).}

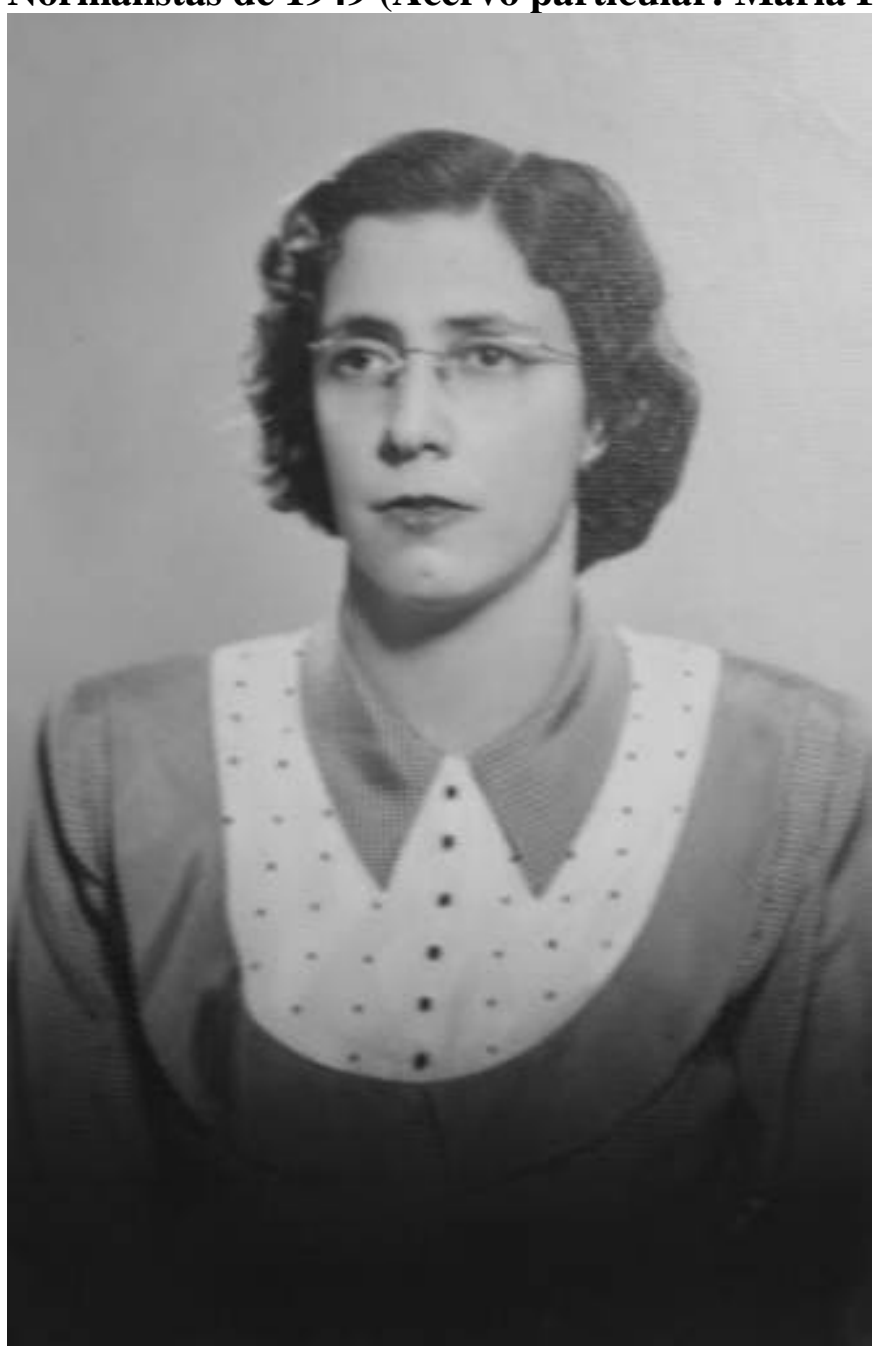

A atuação da Irmã Maria do Rosário foi crucial no momento em que a missão brasileira, em fins da década de 1960, passava por um momento de conquista da autonomia administrativa e apostólica, frente à Casa-Mãe, de Berlaar - Bélgica. 
A Irmã Maria do Rosário Lemos Borges foi a primeira Superiora Provincial da recém-formada Província brasileira, de 1969 a 1972. Foi também Conselheira entre 1985 e 1988. Sua atuação nas diversas funções no interior da Congregação demonstra a versatilidade exigida às Irmãs no desenvolvimento das atividades apostólicas nas localidades atendidas, como serviço exclusivo à causa da Igreja Católica.

O capítulo de 1968, procurou traduzir as novas visões do Concílio Vaticano II nas formas de direção: descentralização e participação dos membros. Enquanto a Dinamarca e o Zaire, como regiões como regiões separadas, continuavam funcionando sob a direção geral de Berlaar, o Brasil que, com dezesseis casas e 200 membros representava quase um quarto da Congregação, tornou-se uma Província autônoma. [...] A superiora provincial e as três conselheiras eram eleitas democraticamente por um período de três anos. Reeleição era possível por um segundo prazo. Uma conselheira era escolhida pela superiora provincial e o conselho completo escolhia depois a ecônoma provincial. Estas nomeações deviam, no entanto, ser confirmadas pela direção geral na Bélgica. O conselho provincial indicava igualmente as mestras de noviças e de junioristas, as quais tinham, quanto ao seu domínio, competência conselheira na direção provincial. $\mathrm{O}$ conselho provincial pode definir suas linhas de direção, de maneira autônoma. Também nos assuntos financeiros a Província funciona de maneira totalmente autônoma. Irmã Maria do Rosário foi a primeira superiora provincial da nova Província brasileira. (SEGERS et al, 1995, p. 403)

Os cursos de formação continuada mais freqüentados pelas Irmãs eram os chamados "Cursos de Férias", de aperfeiçoamento ou de especialização para garantir não só a atualização dos conhecimentos e práticas referentes às atividades profissionais, mas também como garantia para o atendimento às prerrogativas legais.

O Vaticano, através da Congregação de Seminários e Universidades de Estudos, sempre discursou sobre a necessidade da formação contínua e a obtenção dos títulos acadêmicos necessários não apenas para a atuação docente de qualidade, mas também para o cumprimento das legislações pertinentes ao assunto, nos diversos países em que a Igreja Católica atua enquanto mantenedora de educandários.

Em Patrocínio - Minas Gerais, nas décadas em que abrangem o período de atuação dos educandários católicos existentes na cidade até então (o Colégio Dom Lustosa e o Colégio Normal Nossa Senhora do Patrocínio), nota-se a dificuldade em selecionar e recrutar docentes graduados nas áreas específicas dos saberes escolares, assim como em buscar as soluções para a deficiência de formação continuada.

Em geral, os próprios padres e religiosas assumiam as cadeiras das diversas disciplinas do currículo, de forma provisória, no esforço de atender as prerrogativas legais para o funcionamento dos educandários em Patrocínio. Além de ser um centro urbano de dimensões ainda muito reduzidas, e com poucos recursos, Patrocínio ficava relativamente distante dos grandes centros de formação acadêmica do sudeste do país, naquele momento, como Belo Horizonte, Rio de Janeiro e São Paulo.

O artigo $4^{\circ}$ do Decreto-lei no 8.777 (22/01/1946), Lei Orgânica do Ensino Normal, prevê a possibilidade de concessão de registro docente para professores de estabelecimentos localizados em regiões onde não existam em quantidade suficiente de 
diplomados em faculdade de Filosofia, desde que se submetam aos exames de suficiência nas disciplinas pretendidas, sob o juízo do Ministério da Educação e Saúde Pública.

Os pedidos de registro foram encaminhados ao Rio de Janeiro e, depois de algumas tentativas frustradas, houve a concessão de Registros docentes para algumas das religiosas da Congregação das Irmãs do Sagrado Coração de Maria que atendiam aos critérios préestabelecidos.

Foram, então, realizadas algumas ações de formação continuada das religiosas docentes. O conjunto de atividades de formação continuada foi desenvolvido tendo em vista o aprimoramento técnico e pedagógico das religiosas docentes, não apenas do Colégio Normal Nossa Senhora do Patrocínio, mas de muitos outros estabelecimentos de ensino mantidos pela Igreja Católica. Esta instituição em particular se demonstrava muito preocupada em garantir a qualidade dos serviços de ensino não apenas pela reprodução dos saberes técnicos, literários ou científicos, mas também pela garantia de uma importante estratégia de doutrinação moral e religiosa da sociedade.

Por isso, algumas das docentes do Colégio Normal Nossa Senhora do Patrocínio, a partir de fins da década de 1940, envolvidas com a formação continuada empreendida pela Congregação. Por isso, se matricularam no chamado "Curso de Férias", com a finalidade de buscar habilitação docente (disciplinas específicas das áreas de saber, assim como de áreas pedagógicas).

\section{Figura 3 - Colégio Santa Maria (Belo Horizonte) - Primeiro local de funcionamento da Faculdade de Filosofia, Ciências e Letras Santa Maria.}

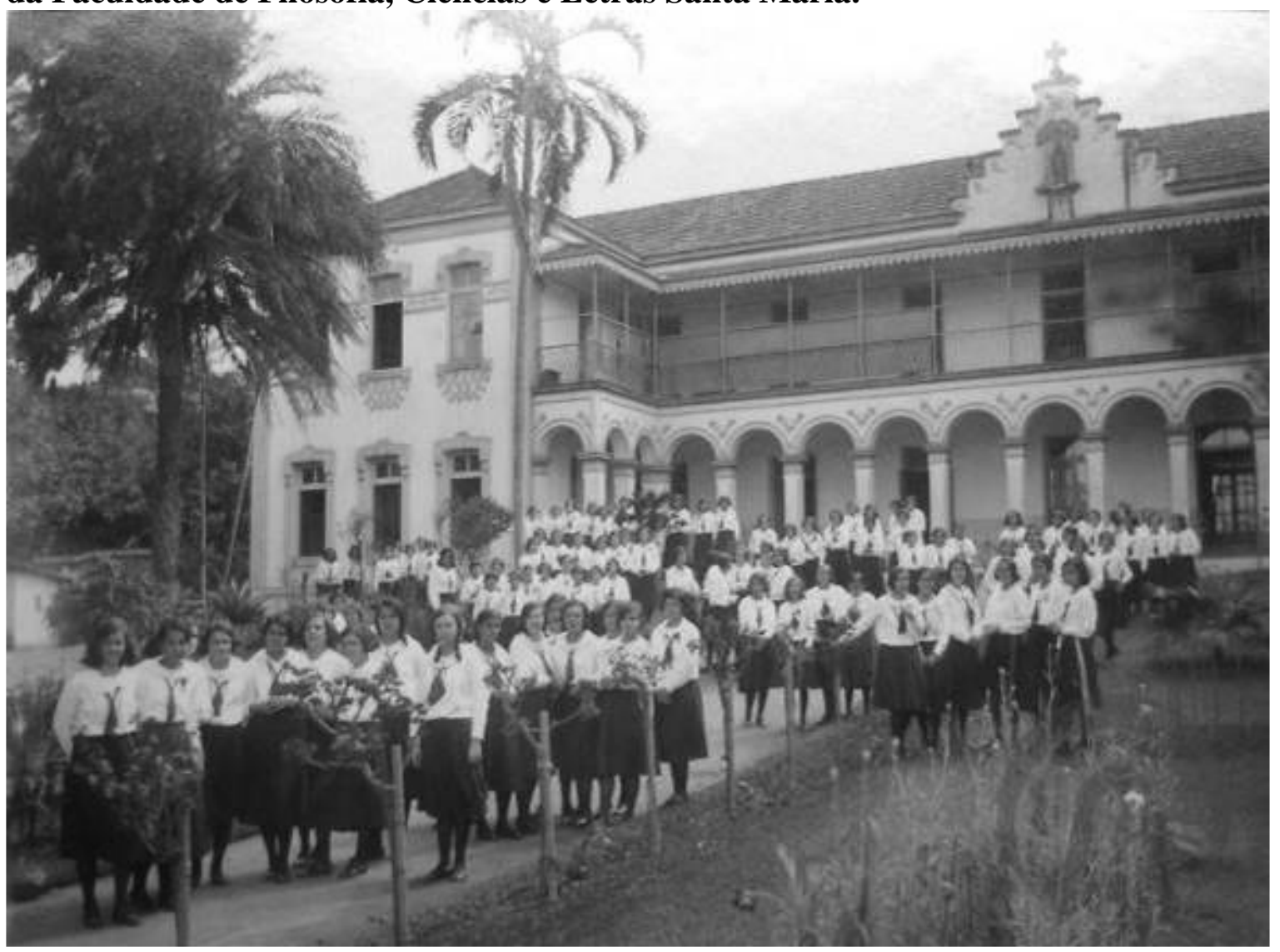

Fonte: http://www.santamariamg.com.br/colegio-santa-maria/o-santa-maria/historico-2-2/. Acesso: $14 / 09 / 2011$. 
O "Curso de Férias" oferecido pela Secretaria de Educação do Estado de Minas Gerais, em colaboração com a Faculdade de Filosofia, Ciências e Letras Santa Maria e com o Instituto de Educação de Minas Gerais. Este foi criado em 1906 para formar originalmente as normalistas em Belo Horizonte. Tais cursos acontecem durante os meses de janeiro e fevereiro e após a sua realização são emitidos os certificados de participação aos cursistas.

Segundo o histórico presente no website da Pontifícia Universidade Católica de Minas Gerais (PUC Minas), as origens da Faculdade de Filosofia, Ciências e Letras Santa Maria se estendem até o início do século XX quando ainda durante a construção da cidade de Belo Horizonte, em 1902, Afonso Pena e outros fundadores buscavam a instalação de uma instituição católica de ensino, capaz de atender à demanda originada com a criação de Belo Horizonte.

Nesse sentido, o Colégio Santa Maria foi fundado no dia 20 de julho de 1903 que, depois de ocupar diferentes locais, se estabeleceu definitivamente na esquina das ruas Pouso Alegre e Jacuí, onde consolidou suas atividades de ensino. Foi aí que se originou a Faculdade de Filosofia, Ciências e Letras Santa Maria, fundada em 1945 e doada em 1949 à Sociedade Mineira de Cultura, futuramente a Universidade Católica de Minas Gerais.

Além da frequiência nos cursos de férias ofertados pela Secretaria de Educação do Estado de Minas Gerais, as religiosas docentes do Colégio Normal Nossa Senhora do Patrocínio também buscaram formação contínua na Faculdade de Filosofia, Ciências e Letras do Instituto Santa Úrsula, Rio de Janeiro, ingressando no Curso de Orientação Educacional.

O Instituto Santa Úrsula foi fundado graças à ação da Congregação das Ursulinas, quando seu Conselho Superior deliberou pela criação do Instituto, cujo subtítulo é Faculdade de Pedagogia, Ciências e Letras do Instituto Santa Úrsula. Foi reconhecido pelo Decreto ${ }^{\circ} 8.057$ de 14 de outubro de 1941.

O projeto de criação do Instituto Santa Úrsula foi apresentado pela Vice-Provincial da Congregação, no dia 14 de dezembro de 1937 ao Cardeal Arcebispo do Rio de Janeiro, Dom Sebastião Leme, com a ajuda de Alceu Amoroso Lima.

Fundamentalmente, de forma geral, o objetivo era fundar um educandário voltado à formação cultural, em nível superior, para o público feminino. De maneira específica, buscava a divulgação da doutrina católica e formação religiosa à juventude. Além do mais, seria uma instituição escolar voltada para religiosas de todo o país aprofundarem seus estudos universitários. Assim,

A nova obra deveria não apenas adequar-se à realidade política e cultural, mas também se orientar pelas diretrizes pastorais do episcopado brasileiro e especificamente, do Arcebispo do Rio de Janeiro. Sob a égide de um selecionado Corpo Docente, a Faculdade de Pedagogia, Ciências e Letras do Instituto Santa Úrsula, a primeira no gênero fundada na Capital da República, preparou-se para ocupar o lugar que lhe competia entre os estabelecimentos de Ensino Superior que incentivavam a cultura verdadeiramente humanística, impregnada do mais puro espírito cristão. A 20 de março de 1939 foi proferida a aula inaugural "Oratio Sapientiae" pelo Frei Sebastião Tauzin OP., traçando magistralmente as linhas gerais da orientação da Faculdade que pode ser resumida no pensamento de Santa Ângela: "Formar professoras antes de abrir escolas". A Faculdade de Pedagogia, Ciências e Letras do Instituto Santa Úrsula, dirigido pelas religiosas Ursulinas da União Romana da Ordem de Santa Úrsula foi oficialmente reconhecida pelo Decreto n ${ }^{\circ} 8057$ de 14.10.1941. No mesmo 
Parecer $N^{\circ} 68$ da Comissão de Ensino Superior destaca-se "muitos dos nomes dos professores indicados são conhecidos e admirados no país e fora dele por suas obras nas especialidades que pretendem ensinar". Para isso o Instituto contou com seleto grupo de professores e orientadores que uniram aos seus dotes intelectuais uma vivência cristã significativa: a Diretora da Faculdade Maria de Santo Agostinho Godivier, OSU; Padre Leonel Franca, S.J.; Reverendo Padre Helder Câmara; Reverendo Frei Sebastião Tauzin, OP; Dr Nelson Roméro; Dr Alcebíades Delamare; Prof. Pierre Deffontaines; Dr Pedro Calmon; Dr Américo Jacobina Lacombe; Dr. Clovis do Rego Monteiro; Dr Alceu Amoroso Lima; Dr Thiers Martins Moreira; Dr Teobaldo Miranda Santos; Dr Pio Benedito Ottoni; D. Lúcia Magalhães e D. Maria Junqueira Schmith.

(Fonte: http://www.usu.br/ProcessoSeletivo/Manual_Candidato.htm. Acesso: 14.09.2011)

Devido à intensa produção intelectual do seu corpo docente, a faculdade das Ursulinas se tornou um ambiente de debates, englobando temáticas como a renovação e a situação da estrutura escolar, a recontextualização filosófica, assim como suas novas correntes e, por conseguinte, do ponto de vista religioso, a própria organização referente à renovação litúrgica, a Ação Católica e a assistência social.

Além do compromisso de buscar qualificação, mesmo durante o período das férias escolares, percebe-se também o cuidado das religiosas da Congregação das Irmãs do Sagrado Coração de Maria de Berlaar em buscar instituições de ensino católicas e que, portanto, comungam dos mesmos valores e diretrizes que divulgam no cotidiano enquanto missionários.

Nota-se que a rede escolar católica buscava condições em aprimorar a interdependência e a associação endógena, procurando a consolidação dos educandários em conjunto. Em geral, boa parte dos formandos são educadores já em atividades de docência, cursistas e alunos de outros educadores, também religiosos.

Essa preocupação reflete coerentemente o interesse de manter sob controle a ideologia propagada, assim como os valores difundidos no desenvolvimento da formação continuada. Portanto, as possibilidades de formação constante e o aprimoramento das habilidades pedagógicas foram bastante valorizadas pela Congregação das Irmãs do Sagrado Coração de Maria de Berlaar.

Participavam também dos cursos de aprimoramento pedagógico, com base na Campanha de Aperfeiçoamento e Difusão do Ensino Secundário, promovida pelo Ministério da Educação e Cultura, por meio de sua Diretoria do Ensino Secundário, assim como as jornadas para diretores e secretários.

Os procedimentos metodológicos utilizados para o desenvolvimento da presente investigação se baseiam na pesquisa bibliográfica; no exame interpretativo de documentos da Igreja Católica Apostólica Romana referentes ao modelo educacional, destacadamente escolar; na investigação das legislações educacionais pertinentes à formação de professores, como a Lei Orgânica do Ensino Normal (1946); e, finalmente, no tratamento de fontes documentais presentes na secretaria do Colégio Normal Nossa Senhora do Patrocínio e nos arquivos pessoais de ex-professores e ex-normalistas, quando foram oportunizadas informações referentes às ações de formação básica e continuada do corpo docente atuante no educandário patrocinense.

Dessa forma, as religiosas da Congregação das Irmãs do Sagrado Coração de Maria, majoritariamente responsáveis pelo ensino das disciplinas no Curso Normal, se dedicaram aos cursos de formação acadêmica, procurando proficiência conteudista, além 
de novas metodologias de ensino e atualização dos saberes técnicos e pedagógicos para o exercício da atividade docente no cotidiano de formação das normalistas de Patrocínio e região. Além do mais, a formação de normalistas no Colégio Normal Nossa Senhora do Patrocínio consistia também em parte da estratégia católica de "restauração" doutrinária, moral e política, buscando a hegemonia dos modelos católicos para a sociedade brasileira.

\section{Referências}

AZZI, Riolando (1992). O altar unido ao trono - um projeto conservador. Coleção História do pensamento católico no Brasil. Vol. 3. São Paulo: Edições Paulinas.

MANACORDA, Mario Alighiero (2004). História da Educação - da Antiguidade aos nossos dias. 11. ed. São Paulo: Cortez Editora.

PIO XI (1929). Carta Encíclica Divini Illius Magistri. Disponível em:

http://www.vatican.va/holy_father/pius_xi/encyclicals/documents/hf_p-

xi_enc_31121929_divini-illius-magistri_po.html. Acesso: 10 de abril de 2011.

SEGERS, Yves et all (1995). 1845 - 1995150 anos Irmãs do Sagrado Coração de Maria de Berlaar Servindo em simplicidade. Lovaina, Bélgica: KADOC, Centro Católico de documentação.

Recebido em janeiro de 2012

Aprovado em março de 2012 